\title{
Ajuga Bracteosa Transgenic Regenerants Display Better Pharmacological Potential
}

\section{Samina Rubnawaz ( $\square$ samina.r.nawaz@gmail.com )}

Department of Biochemistry, Quaid i Azam University, Islamabad, Pakistan https://orcid.org/00000001-9294-2940

\author{
Waqas Khan Kayani \\ University of Kotli Azad Jammu and Kashmir \\ Nosheen Akhtar \\ National University of Medical Sciences \\ Rashid Mahmood \\ Quaid-i-Azam University \\ Furrukh Mehmood \\ Quaid-i-Azam University \\ Asif Khan \\ University of Malaya, Kuala Lumper Campus \\ Bushra Mirza \\ Quaid-i-Azam University
}

\section{Research Article}

Keywords: Ajuga bracteosa, Antioxidants, Genetic transformation, Metabolic profiling, Pharmaceutical properties

Posted Date: June 22nd, 2021

DOI: https://doi.org/10.21203/rs.3.rs-635255/v1

License: (c) (i) This work is licensed under a Creative Commons Attribution 4.0 International License.

Read Full License 


\section{Abstract}

Ajuga bracteosa Wall. ex Benth is an endangered medicinal herb used against different ailments in folklore medicines. Here, we aimed to create a new insight to the fundamental mechanisms of genetic transformation in the ethnomedicinal usage of this plant. We transformed the plant with rol genes of Agrobacterium rhizogenes and raised the regenerants from the hairy roots. The transgenic regenerants were screened for in vitro antioxidant activities, a range of in vivo assays, and linked the activities with elemental analysis, polyphenol content and different phytochemicals found through HPLC. Among 18 polyphenolic standards, kaempferol was found most abundant in all transgenic lines (up to $101.26 \pm 6$ $\mu \mathrm{g} / \mathrm{mg}$ ). Furthermore, among all tested plant extracts, transgenic line 3 (ABRL3) showed maximum phenolics (13.39 $\pm 2 \mu \mathrm{g} \mathrm{GAE} / \mathrm{mg})$ and flavonoids content $(4.75 \pm 0.16 \mu \mathrm{g} \mathrm{QE} / \mathrm{mg})$. ABRL3 also demonstrated potent total antioxidant capacity $(8.16 \pm 1 \mu \mathrm{g} \mathrm{AAE} / \mathrm{mg})$, total reducing power, $(6.60 \pm 1.17$ $\mu \mathrm{g} \mathrm{AAE} / \mathrm{mg}), \mathrm{DPPH}$ activity $\left(\mathrm{IC}_{50}=59.5 \pm 0.8 \mu \mathrm{g} / \mathrm{mL}\right)$, hydroxyl ion scavenging $\left(\mathrm{IC}_{50}=122.5 \pm 0.90 \mu \mathrm{g} / \mathrm{mL}\right)$, and iron chelating power $\left(\mathrm{IC}_{50}=154.8 \pm 2 \mu \mathrm{g} / \mathrm{mL}\right)$ among all plants. Transformed plant extracts also produced significant analgesic, anti-inflammatory, anticoagulant, and antidepressant properties in in vivo mice model as compared to control untransformed plant material. Additionally, no abnormal behavior or lethality was observed in any animal tested. In conclusion, transgenic regenerants of $A$. bracteosa pose better pharmacological properties under the effect of ro/genes as compared to wild type plants.

\section{Introduction}

Medicinal plants have been used in traditional medicines for thousands of years and they contain a wide variety of biologically active plant products called secondary metabolites. In the last decade, the potential toxicity of synthetic drugs led to a resurgence of the use of these metabolites as a facile and economical alternative approach [1]. According to the World Health Organization (WHO), approximately, 80\% population of developing countries depends on plant products to alleviate and treat serious ailments [2].

Free radicals, such as reactive oxygen and nitrogen species, produced in the human body can be a root cause of aging, rheumatism, malignancies, diabetes, cardiovascular, and neurodegenerative disorders [3]. Higher rate of incidence of these diseases triggered the research of natural antioxidants and various studies have suggested that dietary polyphenols are the most abundant antioxidants in nature [4]. These polyphenols can directly scavenge free radicals, chelate metal ions, and inhibit their pro-oxidant activities, thus reducing the risk of chronic metabolic diseases. Moreover, polyphenols also possess antiinflammatory, anti-thrombotic, and analgesic activities [5]. Likewise, different trace elements not only improve plant immunity but also provide scaffolding for antioxidant enzymes as cofactors in humans. Hence, it is dire need to thoroughly investigate different herbal extracts for their antioxidant properties to develop new drugs [6].

Ajuga bracteosa is considered elixir to a variety of ailments and it is found in hilly areas of Pakistan, Nepal, Kashmir, India, and the Himalayan region. Extensive literature survey reveals that different extracts of $A$. bracteosa have a variety of pharmacological activities. It is used to cure skin infections, respiratory 
issues, digestive problems, malaria, protozoal diseases, diabetes mellitus, hepatitis, arthritis, epilepsy, inflammation, neurological disorders, and cancer $[7,8,9,10]$. This medicinal importance is due to a repertoire of metabolites such as essential oils, ecdysteroids, terpenoids, phenolics, flavonoids, and withanolides characterized in this plant [11].

Root oncogenic loci ( $\mathrm{rol})$ genes are well known for the upregulation of secondary metabolism [12]. Different rol genes have different induction capacity of secondary metabolites [13] and a lot of the pharmacological activities are linked to the amount of the secondary metabolites produced in the medicinal plants [14]. We hypothesize that the amount of these secondary metabolites biosynthesized de novo in $A$. bracteosa could be enhanced and hence the better pharmacological effects could be attained. Considering that, we transformed $A$. bracteosa with rolABC genes of Agrobacterium rhizogenes and hairy roots were produced. To resolve the issue of organ specificity of certain metabolites, intact plants (regenerants) were regenerated from these transgenic hairy root lines and their extracts were screened for antioxidant activities. Multiple in vivo activities including analgesic, anti-inflammatory, antidepressant, and anticoagulant activity were evaluated using BALB/c mice. In the continuation of our previous study [15], estimation of essential elements of transformed regenerated plants of $A$. bracteosa by atomic absorption spectrophotometry and HPLC fingerprinting of polyphenol content was performed to support our results.

\section{Materials And Methods}

\section{Source of plant}

The plant material was collected from the premises of Quaid-i-Azam University, Islamabad, Pakistan. These plants were identified by Prof. Dr. Rizwana Aleem Qureshi (Taxonomist), Department of Plant sciences, Quaid-i-Azam University, Islamabad. A voucher specimen number (HPM-460) was deposited in the herbarium of Quaid-i-Azam University. Fresh green plants were surface sterilized and tissue cultured on Murashige and Skoog (MS) medium. Transgenic hairy roots were generated through rolABC containing $A$. rhizogenes mediated transformation. Intact plants were regenerated from hairy roots by following the previously optimized method in our lab [16]. Polymerase chain reaction (PCR) was performed for the confirmation of transformation and stable integration of rol genes in transformed roots and regenerants $[15,16]$. Untransformed tissue cultured plants and transgenic regenerants of $A$. bracteosa plants were used in this study.

\section{Elemental Analysis}

For the digestion of leaf samples, an earlier reported method [17] was employed with slight modifications. Powdered leaf samples were weighed (100 mg each) and heated in an oven at $110^{\circ} \mathrm{C}$ in a china dish for the removal of moisture. The dried samples were heated at $550^{\circ} \mathrm{C}$ for $4 \mathrm{~h}$ and then cooled at room temperature. Then Nitric acid (6 M; $10 \mathrm{~mL}$ ) was added for acid digestion. After filtration, the solution was diluted up to a $25 \mathrm{~mL}$ mark with deionized water. Reference standards of 12 micro and macro elements (Sigma-Aldrich, USA), were used to quantify the essential elements and to find the possible accumulation 
of hazardous heavy metals in A. bracteosa. Estimation of all elements was carried out on Fast Sequential Atomic Absorption Spectrometer (Varian 240AA FS-Australia). The operating parameters for working elements were optimized according to the manufacturer's recommendations.

\section{Crude extracts preparation for biological activities}

Aerial parts of three independent transgenic lines (ABRL1, 2, and 3) and in vitro grown untransformed A. bracteosa plants (WT) were shade dried after rinsing with water. Leaves were ground and $1 \mathrm{~g}$ powdered material was allowed to set in a mixture of methanol: chloroform $(1: 1 ; 5 \mathrm{~mL})$. After $1 \mathrm{~h}$ the mixture was sonicated for 10 min followed by 20 min of shaking and the process was repeated three times. Finally, the plant extracts were filtered and pooled filtrates were dried, weighed, and stored at room temperature for further analysis.

\section{Phytochemical profiling}

\section{Qualitative assays}

Crude extracts of $A$. bracteosa were evaluated for the presence of major families of secondary metabolites such as alkaloids, glycosides, flavonoids, phenols, tannins, saponins, terpenoids, coumarins, betacyanin ( $\beta$-cyanin), anthocyanin, and sterols using standard qualitative procedures based on coloring reaction and/or precipitation [18].

\section{Quantitative assays}

\section{Estimation of total phenolics and flavonoids content}

The total phenolic content (TPC) was calculated by Folin-Ciocalteu (FC) assay using gallic acid as standard [19]. Briefly, $20 \mathrm{mg}$ of each dried extract was dissolved in $1 \mathrm{~mL}$ of DMSO. Gallic acid (1 mg, Merk) was dissolved in $1 \mathrm{~mL}$ of DMSO and further diluted. In this experiment $5 \mu \mathrm{L}$ of plant extract was mixed with $98 \mu \mathrm{L}$ of 10 times diluted FC reagent in 96 well plate (Thermo Scientific). After $5 \mathrm{~min}, 98 \mu \mathrm{L}$ of $6 \%$ sodium carbonate was added and incubated at $25^{\circ} \mathrm{C}$ for $90 \mathrm{~min}$. Finally, the absorbance was measured at $630 \mathrm{~nm}$ with a microtiter plate reader (Elx 800). TPC was expressed as gallic acid equivalents ( $\mu \mathrm{g} \mathrm{GAE} / \mathrm{mg}$ dry weight of plant extract). Total flavonoid content (TFC) was determined by already optimized colorimetric method [20] with slight modifications. $5 \mu \mathrm{L}$ of each extract $(20 \mathrm{mg} / \mathrm{mL})$ was mixed with equal volumes of potassium acetate $(1 \mathrm{M})$ and $10 \%$ aluminium chloride (20 $\mu \mathrm{L}$ each). Then $155 \mu \mathrm{L}$ of distilled water subsequently added and mixture was left at $37{ }^{\circ} \mathrm{C}$ for half an hour. After incubation, absorbance was determined at $405 \mathrm{~nm}$ and TFC was expressed as quercetin equivalents ( $\mu \mathrm{g}$ QE/ mg extract).

\section{Quantification of polyphenols by RP-HPLC}

For RP-HPLC analysis, polyphenols were extracted from aerial parts of wild plant and transgenic lines according to previously reported procedure [21]. HPLC-DAD system (Agilent technology; Germany) was 
attached to an analytical column (Sorbex RXC-8) with the dimensions, $5 \mu \mathrm{m}, 4.6 \times 250 \mathrm{~mm}$, for separation of polyphenols. This separation was achieved using two mobiles phases; water: methanol: acetonitrile: acetic acid (85: 10: 5: 1) were present in mobile phase A while mobile phase B included methanol: acetonitrile: acetic acid (60: 40: 1 ). The process was operated by regulating the gradient program as follows; (t $(\mathrm{min}), \% \mathrm{~B})(0,50)(20,50)(25,100)(40,100)$ with $1 \mathrm{ml} / \mathrm{min}$ flow rate at 350 bars. $20 \mu \mathrm{L}$ of each crude extract and standard was injected. Identification and quantification of polyphenols were carried out by comparison of the peaks of each metabolite with particular retention time in the standards.

\section{In vitro antioxidant assays}

Potent antioxidant activities from crude extracts was detected by various antioxidant assays [22]. For Diphenyl-2-picryl-hydrazyl (DPPH) radical scavenging activity, ascorbic acid (Merk, Germany) was used as positive control. Phospho molybdate method was used for determination of total antioxidant activity.

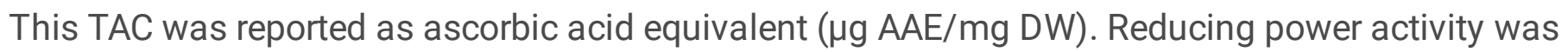
recorded as ascorbic acid equivalent. The $\mathrm{OH}$ scavenging potential of extracts was determined by classical thiobarbituric acid (TBA) and deoxyribose based method. In this study, Gallic acid was used as positive control. The Ferrous ion $\left(\mathrm{Fe}^{++}\right)$chelating ability of plant extracts was also investigated. DMSO was used as negative control in all antioxidant assays.

\section{Experiment design for in vivo assays}

For the experiment, healthy male BALB/c albino mice (4-6 weeks; $25-30 \mathrm{~g}$ ) were procured from the $\mathrm{NIH}$, Islamabad, Pakistan. Test mice were maintained under controlled environmental conditions $\left(23.0 \pm 2.0^{\circ} \mathrm{C}\right.$ temperature; 60 - 70\% of relative humidity; $12 \mathrm{~h}$ light/dark cycle) in the Primate facility Quaid-i-Azam University (QAU), Islamabad, Pakistan. All the mice were fed with pellet diet and had free access to water ad libitum. All the experiments were approved by the Animal Ethical Committee, QAU (BEC-FBS-QAU2019157).

Plant extracts and standard compounds were prepared in normal saline $(0.9 \% \mathrm{NaCl})$ and administered orally according to mice body weight. In these experiments, 30 male mice were randomly divided into 6 groups as following:

Normal control group: $200 \mathrm{mg} / \mathrm{kg}$ normal saline.

Positive control group: $10 \mathrm{mg} / \mathrm{kg}$ standard drugs.

Test group-1: $200 \mathrm{mg} / \mathrm{kg}$ crude extract of wild type plant (WT).

Test group-2: $200 \mathrm{mg} / \mathrm{kg}$ crude extract of ABRL1.

Test group-3: 200 mg/kg crude extract of ABRL2.

Test group-4: $200 \mathrm{mg} / \mathrm{kg}$ crude extract of ABRL3. 


\section{Acute toxicity test}

Before performing in vivo experiments, animals were tested for toxic effects of $A$. bracteosa plant extracts. The oral administration of plant crude extracts (up to $1 \mathrm{~g} / \mathrm{kg}$ ) proved to be non-toxic and did not produce mortality for the next $24 \mathrm{~h}$. Guidelines 425 of the Organization for Economic Corporation and Development (OECD) were strictly followed during the study.

\section{In vivo biological activities}

For all in vivo assays, previously reported methods [8] were employed and normal saline was used as negative control. For analgesic activity, the standard drug, aspirin was used as a positive control. The anti-inflammatory activity of $A$. bracteosa crude extracts were assessed through carrageenan-induced hind paw edema model. Here, Diclofenac potassium was used as positive control. Tail suspension test, a simple and inexpensive method, was used to assess anti-depressant activity. Data collected in TST were expressed as arithmetic means of immobility time for each experimental group. Whereas, capillary tube was used to analyze the anticoagulation activity of the crude extracts of $A$. bracteosa in mice.

\section{Statistical analysis}

All the experiments were performed in triplicates. One way analysis of variance (ANOVA) was used to find variability between data. $\mathrm{IC}_{50}$ values were calculated through GraphPad Prism Software Version 7.0 (GraphPad Prism ${ }^{\circledR}$ Software, Inc. San Diego, CA, USA) by plotting transformed inhibitors vs log values of inhibition. PAST 4.03 was used for principal component analysis (PCA). $p>0.05$ was considered significant and data was represented as mean of 3 values \pm SD (Standard Deviation).

\section{Results}

\section{Elemental analysis}

The elemental screening of transformed and untransformed $A$. bracteosa digested extracts revealed the presence of 10 elements, commonly found in plants, as listed in Table 1. Data shows that transgenic line 3 (ABRL3) is enriched with 3 macro-elements: sodium $3.94 \pm 2 \mu \mathrm{g} / \mathrm{mg}$ dry weight (DW), potassium 13.09 $\pm 2 \mu \mathrm{g} / \mathrm{mg} \mathrm{DW}$, and calcium $1.95 \pm 0.5 \mu \mathrm{g} / \mathrm{mg}$ DW. While magnesium is more abundant in transgenic line $1(2.15 \pm 0.3 \mu \mathrm{g} / \mathrm{mg} \mathrm{DW})$. Likewise, the highest amounts of all micro-elements are found in ABRL3 except chromium which is more prevalent in ABRL1. On the other hand, untransformed wild type (WT) plant extract has the least concentrations of all elements ranging from $0.004 \pm 0.01 \mu \mathrm{g} / \mathrm{mg}$ to $8.06 \pm$ $0.3 \mu \mathrm{g} / \mathrm{mg}$ of dry sample. We also observed that cadmium and lead are below the detection limit in all samples.

\section{Qualitative screening}

Qualitative analyses showed the presence of medicinally important phytoconstituents in the methanol: chloroform extracts of $A$. bracteosa summarized in Table 2 . These findings suggest that alkaloids, 
phenolics, flavonoids, and glycosides are present in all extracts in a larger amount. Whereas tannins and saponins are found in moderate amounts. Anthocyanin, B-cyanins, coumarins, and sterols were absent in all extracts while, terpenoids were identified only in transgenic lines.

\section{Quantitative analyses}

\section{Determination of TPC and TPC}

TPC and TFC were calculated as $\mu \mathrm{g}$ of gallic acid and quercetin equivalents/mg dry extract by using calibration curves of gallic acid $\left(y=0.0163 x-0.0130, R^{2}=0.9983\right)$ and quercetin $(y=0.0517 x+0.0172$, $\left.R^{2}=0.9991\right)$ respectively (Figure 1$)$. In this study, ABRL3 has maximum quantity of phenolics $(13.39 \pm$ $2 \mu \mathrm{g} \mathrm{GAE} / \mathrm{mg} \mathrm{DW})$ followed by ABRL1 (11.28 $\pm 1 \mu \mathrm{g} \mathrm{GAE} / \mathrm{mg} \mathrm{DW})$, and ABRL2 (8.31 $\pm 1.5 \mu \mathrm{g} \mathrm{GAE} / \mathrm{mg} \mathrm{DW})$. Whereas, WT contains minimum amount of phenolics (4.803 $\pm 0.04 \mu \mathrm{g} \mathrm{GAE} / \mathrm{mg}$ DW). Similarly, TFC ranges from the highest value in ABRL3 $(4.75 \pm 0.16 \mu \mathrm{g} \mathrm{QE} / \mathrm{mg} \mathrm{DW})$ to the lowest value in WT (1.55 \pm $0.08 \mu \mathrm{g}$ QE/mg DW).

\section{RP-HPLC}

Among the eighteen polyphenolic standards tested through RP-HPLC, twelve were detected in all extracts of $A$. bracteosa. Kaempferol was most abundant in all transgenic samples ranging from $78.6 \pm 5 \mu \mathrm{g} / \mathrm{mg}$ in ABRL2 to $101.26 \pm 6 \mu \mathrm{g} / \mathrm{mg}$ in ABRL3. WT contained the highest amount of ferulic acid $(75.55 \pm 3$ $\mu \mathrm{g} / \mathrm{mg})$ and the lowest amount of rutin $(0.63 \pm 0.5 \mu \mathrm{g} / \mathrm{mg})$. Cinnamic acid was least abundant in all transformed lines with $4.36 \pm 0.5 \mu \mathrm{g} / \mathrm{mg}$ in ABRL1, $5.47 \pm 0.2 \mu \mathrm{g} / \mathrm{mg}$ ABRL2, and $6.09 \pm 0.3 \mu \mathrm{g} / \mathrm{mg}$ in ABRL3 (Table 3). Overall, ABRL3 has a predominantly higher content of all polyphenols screened in this study as represented by chromatogram in Supplementary Figure 1.

\section{In vitro antioxidant assays}

\section{TAC and TRP}

Total antioxidant capacity (TAC) and total reducing power (TRP) ) of samples against ascorbic acid equivalent are given in Figure 2. Results showed that ABRL3 exhibited the maximum total antioxidant capacity ( $8.16 \pm 1 \mu \mathrm{g} \mathrm{AAE} / \mathrm{mg} \mathrm{DW})$ while minimum antioxidant capacity was shown by WT $(4.18 \pm 0.16$ $\mu \mathrm{g} \mathrm{AAE} / \mathrm{mg}$ DW). TAC was found to decrease in the order ABRL3 > ABRL1 > ABRL2 > WT. All the transgenic lines showed significantly increased antioxidant activity $(p<0.01)$ compared to wild plants. Data also shows that ABRL3 exhibited the highest reduction power of $6.60 \pm 1.17 \mu \mathrm{g} \mathrm{AAE} / \mathrm{mg}$ DW followed by $5.8 \pm 1 \mu \mathrm{g} \mathrm{AAE} / \mathrm{mg}$ DW in ABRL1. TRP followed the as that of TAC in all plant extracts. However, TRP was significantly higher $(p<0.01)$ in transgenic regenerants than wild control plants.

\section{DPPH Radical scavenging assay}


The percent scavenging activity of the extracts were evaluated using DPPH free radical scavenging assay and $I_{50}$ values were calculated (Figure $3 \mathrm{a}$ ). $I \mathrm{IC}_{50}$ values varied in a concentration-dependent manner however, all extracts showed higher $\mathrm{IC}_{50}$ values than ascorbic acid $\left(\mathrm{IC}_{50} 39.3 \pm 1 \mu \mathrm{g} / \mathrm{mL}\right)$, used as positive control. The minimum IC ${ }_{50}$ values were exhibited by ABRL3 $(59.5 \pm 0.8 \mu \mathrm{g} / \mathrm{mL})$ followed by ABRL1 (97.64 $\pm 0.5 \mu \mathrm{g} / \mathrm{mL}$ ). Overall, order of $I_{50}$ values was ABRL3 $<A B R L 1<A B R L 2<W T$. The DPPH radical scavenging activity of different extracts presented good correlation with $\operatorname{TPC}\left(\mathrm{R}^{2}=0.9627^{\star \star *}, p<0.001\right)$ and moderate correlation with TFC $\left(\mathrm{R}^{2}=0.7627^{\star *}, p<0.01\right)$ as shown in Figure $3 \mathrm{~d}$.

\section{Hydroxyl ion scavenging assay}

All extracts of $A$. bracteosa scavenged ' $\mathrm{OH}$ radicals while lowest $\mathrm{IC}_{50}$ values were recorded for $A B R L 3$ $(122.5 \pm 0.90 \mu \mathrm{g} / \mathrm{mL})$ and ABRL2 $(129.7 \pm 2 \mu \mathrm{g} / \mathrm{mL})$ followed by ABRL1 $(138.4 \pm 1 \mu \mathrm{g} / \mathrm{mL})$, whereas, the highest IC $\mathrm{IC}_{50}$ was observed for WT $(1056.9 \pm 4 \mu \mathrm{g} / \mathrm{ml})$. IC $\mathrm{C}_{50}$ of all extract samples were significantly different from the standard gallic acid $(81.1 \pm 4 \mu \mathrm{g} / \mathrm{mL})$ as given in Figure $3 \mathrm{~b}$. A highly significant correlation was observed with TPC $\left(R^{2}=0.9312^{\star \star \star}, p<0.001\right)$ and moderate correlation with TFC $\left(R^{2}=\right.$ $0.8158 * *, p<0.01$ ) (Figure 3d).

\section{Ferrous ion chelating activity}

In this study, the finest values for $\mathrm{IC}_{50}$ were exhibited by ABRL3 $(154.8 \pm 2 \mu \mathrm{g} / \mathrm{ml})$ followed by ABRL2 $(179.2 \pm 1 \mu \mathrm{g} / \mathrm{mL})$. Overall, order of $\mathrm{IC}_{50}$ of ABRL3 $<$ ABRL2 $<$ ABRL $1<W T$ was observed (Figure $3 \mathrm{c}$ ). The iron chelating activity of various extracts showed good correlation with $\operatorname{TPC}\left(\mathrm{R}^{2}=0.9159 * \star *, p<0.001\right)$ and moderate correlation with TFC $\left(R^{2}=0.8243 * \star, p<0.01\right)$ as given in Figure $3 d$.

\section{In vivo assays on BALB/c mice}

\section{Analgesic activity}

The crude extracts of transgenic $A$. bracteosa plants showed a delayed latency period and increased analgesic activity in BALB/c mice. Aspirin (positive control) and crude extracts displayed a timedependent activity on a hot plate by suppressing nociceptor activity in mice (Figure 4a). Maximum activity was observed after $1 \mathrm{~h}$ of oral dose in ABRL3 (87.3 $\pm 3 \%$ ) followed by aspirin (85.66 $\pm 4 \%$ ). Whereas, normal saline-treated mice (negative control) produced the least significant analgesic effect (13 $\pm 4 \%)$. ABRL1 and ABRL2 also demonstrated increased activity (76 $\pm 3 \%$ and $74 \pm 2 \%$ ) compared to the wild type control group $(41 \pm 3 \%)$.

\section{Anti-inflammatory activity}

Pain and inflammation are often linked to each other. Therefore, crude extracts were also tested for antiinflammatory activity against carrageenan-induced hind paw edema in BALB/c mice. Observations were made after $1 \mathrm{~h}, 2 \mathrm{~h}$, and $3 \mathrm{~h}$ of oral dose for edema treatment. Diclofenac potassium was used as a positive drug and showed $77.6 \pm 3 \%$ activity after $3 \mathrm{~h}$ post dosage. ABRL3 revealed the highest anti- 
inflammatory activity ( $82.3 \pm 2 \%)$ while WT manifested the lowest activity $(46.6 \pm 2 \%)$ among all tested samples (Figure 4b).

\section{Antidepressant activity}

The potential antidepressant activity of $A$. bracteosa crude extracts was evaluated in mice by tail suspension test and results are displayed in Figure 4c. All transgenic lines exhibited enhanced antidepressant activity compared to wild type and positive control (Fluoxetine-HCl). ABRL3 demonstrated lowest immobility time of $38.3 \pm 2 \mathrm{sec}$ followed by $45.7 \pm 3 \mathrm{sec}$ in ABRL1 and $63.3 \pm 4 \mathrm{sec}$ in ABRL2.

\section{Anticoagulant activity}

Anticoagulant activity of wild type and transgenic lines of $A$. bracteosa is shown in Figure $4 \mathrm{~d}$. Transgenic lines delayed blood clotting from $2.46 \mathrm{~min}$ in negative control to $4.51 \mathrm{~min}, 5.40 \mathrm{~min}$, and 5.41 in ABRL1, $A B R L 2$, and ABRL3 treated mice respectively. WT crude extracts were least effective among all plant extracts with a clotting time of $3.3 \mathrm{~min}$.

\section{Discussion}

The plant kingdom consist of countless species with number of uses in medicines. They contain valuable secondary metabolites demonstrating anti-inflammatory, anticancer, antioxidant antidiabetic and/or antimicrobial properties [23]. The growing demand for these plant secondary metabolites forces the use of new green biotechnology tools to create new, more productive in vitro transgenic plant cultures [24]. This study reports the examination of the potential role of rolABC genes in increasing the production of secondary metabolites and compares the pharmaceutical efficacy of transgenic regenerants and in vitro grown untransformed $A$. bracteosa plants.

Minerals are requisite for disease resistance and normal physiology of the human body; however, high concentrations could be a health risk. Major elements including sodium, potassium, calcium, and magnesium are involved in protein synthesis, nerve transmission, bone development, muscle contraction, and enzyme activation [25]. Here we found that all studied elements were below the maximum permissible limit as recommended by WHO and European pharmacopeia [26]. Among 10 detected elements, potassium was most abundant in all samples. However, the $\mathrm{Na} / \mathrm{K}$ ratio was below 1 which is required to maintain normal blood pressure [27]. Only minute amounts of 6 trace elements were detected. These trace elements have well reported anti-inflammatory, antianemia, antidiabetic, and anticancer properties [28].

Next, phytochemical analysis was carried out to investigate the effects of transformation on secondary metabolite production. Qualitative assays screened several medicinally active molecules in A. bracteosa based on their polarities. Considerable amounts of alkaloids, phenolics, flavonoids, and glycosides were present in all extracts. These phytoconstituents possess antimicrobial, antioxidant, anti-inflammatory, and anticancer properties [29]. Saponins and tannins used as astringents, hepaprotective, 
cardioprotective, and anticancer agents [30] were present in moderate quantities. The presence of terpenoids in transgenic plants can impart antioxidant, antibacterial, antiviral, chemoprotective, and neuroprotective characters $[31,32]$ to these transgenics.

The antioxidant activity of phenolics and flavonoids primarily depends on the presence of hydroxyl groups [33]. Current study demonstrated significantly higher values of TPC and TFC in transformed regenerants as compared to untransformed plants. Our observations are in accordance with the studies reporting enhanced TPC and TFC of Artemisia dubia, A. annua, and Lactuca sativa plants transformed with rolABC genes $[20,34,35]$.

RP-HPLC delineated a marked surge in polyphenols of transformed plants than their untransformed counterparts. These differences support our previous findings indicating that rol $A B C$ genes enhanced the expression of biosynthetic pathway genes in transformed regenerants of $A$. bracteosa [15]. We found that ABRL3 presented highest expression of $\beta$-hydroxy $\beta$-methylglutaryl-CoA reductase (HMGR), farnesyl diphosphate synthase (FDS), 4-hydroxy-3-methyl-but-2-enyl pyrophosphate synthase (HDS), and phenylalanine ammonia lyase (PAL) genes owing to significant phenolic content and antioxidant activity of this line. Higher expression of the metabolic pathway genes can easily be correlated to the higher production of phytoecdysteroids and hence the polyphenols contents. These polyphenols are reported to prevent aging and age related disorders such as cancer, cardiac malfunctions, diabetes, neurodegenerative problems, and inflammatory disorders [3]. Their protective mechanisms involve suppression of oxidative stress, maintenance of Nuclear Factor Kappa B (NF-KB) and interleukins (IL-1 $\beta$ ), activation of gluconeogenesis, inhibition of angiogenesis, and cyclooxygenases (COX-1 and COX-2) [36]. Our results show that six polyphenol markers, namely, plumbagin, thymoquinone, catechin, emodin, gentisic acid, and luteolin were below the detection limit in all crude extracts. However, some earlier studies [10] reported catechin in ethyl acetate and aqueous fractions of $A$. bracteosa. These findings are likely to be related to diverse nature of metabolites and polarity in different solvent systems [37].

All extracts were evaluated for TAC, TRP, and antioxidant activity through DPPH, hydroxyl radical scavenging and iron chelating power assays. Transgenic lines fared better for reducing power and antioxidant activity than untransformed plants. Similar pattern of results was found in Artemisia annua [38] and lettuce [39] plants transformed with different ro/ genes. We observed a significantly positive correlation between antioxidant activities and plant phenolics. Whereas moderate correlation with TFC suggests that antioxidant properties are attributed to higher phenolics than flavonoids content [10].

Hot plate assay is simple and sensitive method to assess anti-nociceptive drugs to relieve pain [22]. The results of analgesic activity showed that transgenic plant extracts protected mice from visceral pain and produced comparable effects to standard drug aspirin. Nonsteroidal anti-inflammatory drugs (NSAIDs) can be used to treat inflammation associated with pain. However, their overuse can lead to serious side effects. Therefore, herbal products are used as an alternative to antagonize inflammatory agents [22]. In 
current study $A$. bracteosa extracts reduced the carrageenan induced edema in mice following the same mechanism as NSAIDs. Different studies suggest that withanolides and phenolics present in A. bracteosa inhibit activity of prostaglandins and $\operatorname{COX}[40,41]$. Terpenoids, phytoecdysteroids, and phenolics attribute to anti-depressant and anticoagulant properties of transformed $A$. bracteosa plant extracts. Thus, this plant can be a potent agent to treat neurodegenerative and thrombolytic disorders $[8,20]$. Our findings are in agreement with former results [39] verifying that ro/genes increased pharmaceutical value of methanolic extracts of transformed lettuce in rats.

\section{Conclusions}

In conclusion, present findings suggest that transgenic $A$. bracteosa plants are a rich source of essential elements and polyphenols. Overall, all transgenic lines showed significant antioxidant, analgesic, antiinflammatory, antidepressant, and anticoagulant activities as compared to the untransformed wild type plant extracts. We could see that rolgenes influenced positively the production of active secondary metabolites and this could be linked to the enhanced activities exhibited by the transgenic plant extracts. This study provides more rationalized scientific reasons for the folklore use of this plant. However, further investigations are needed to understand the underlying protective mechanisms.

\section{Declarations}

\section{Ethics approval and consent to participate}

Animal study was approved by the Animal Ethical Committee, Quaid i Azam university, Islamabad, Pakistan (BEC-FBS-QAU2019-157).

\section{Consent for publication}

Not applicable

\section{Availability of data and material}

The datasets used and/or analyzed during the current study are available from the corresponding author on reasonable request.

\section{Competing interests}

The authors declare that they have no competing interests.

\section{Funding}

The funders had no role in study design, data collection and analysis, decision to publish, or preparation of the manuscript.

\section{Authors' contributions}


SR and BM designed the project. SR carried out the experimental work. NA and RM analyzed the data. FM and AK helped in HPLC analysis of transgenics. SR wrote the manuscript while WKK and BM proofread and critically evaluated it. BM supervised the entire study. All authors have read and approved the final manuscript.

\section{Acknowledgement}

We are thankful to Dr. Ihsan-ul-Haq, Assistant Professor, Department of Pharmacy, Quaid-i-Azam University, Islamabad, Pakistan for providing polyphenol standards and extending the HPLC facility.

\section{References}

[1] H Yuan, Q Ma, L Ye, G Piao. The traditional medicine and modern medicine from natural products. Molecules, 21 (5) (2016), pp. 559

[2] A Singh, P Dwivedi. Methyl-jasmonate and salicylic acid as potent elicitors for secondary metabolite production in medicinal plants: A review. J Pharmacogn Phytochem, 7 (2018), pp. 750-757

[3] D Stagos. Antioxidant activity of polyphenolic plant extracts. Antioxidants, 9 (1) (2020), pp. 19

[4] P Poprac, K Jomova, M Simunkova, V Kollar, CJ Rhodes, M Valko. Targeting free radicals in oxidative stress-related human diseases. Trends Pharmacol Sci, 38 (2017), pp. 592-607

[5] SV Luca, I Macovei, A Bujor, A Miron, K Skalicka-Woźniak, AC Aprotosoaie, et al. Bioactivity of dietary polyphenols: The role of metabolites. Crit Rev Food Sci Nutr, 60 (2020), pp. 626-659

[6] AN Swargiary, PU Nath, BI Basumatary, DU Brahma. Phytochemical, antioxidant, and trace element analysis of anthelmintic plants of North-East India. Int J Pharm Pharm Sci, 9 (2017), pp. 228-232

[7] G Kaithwas, R Gautam, SM Jachak, A Saklani. Antiarthritic effects of Ajuga bracteosa Wall ex Benth. in acute and chronic models of arthritis in albino rats. Asian Pac J Trop Biomed, 2 (2012), pp. 185188

[8] WK Kayani, E Dilshad, T Ahmed, H Ismail, B Mirza. Evaluation of Ajuga bracteosa for antioxidant, anti-inflammatory, analgesic, antidepressant, and anticoagulant activities. BMC Complement Altern Med, 16 (2016), pp. 375

[9] S Qasim, AM Uttra, UH Hasan, A Batool. Evaluation of anticonvulsant potential of aqueous methanolic extract and various fractions of Ajuga bracteosa wall. J Exp Appl Anim Sci, 2 (2017), pp. 137-146

[10] SS Zahra, M Ahmed, M Qasim, B Gul, M Zia, B Mirza, IU Haq. Polarity based characterization of biologically active extracts of Ajuga bracteosa Wall. ex Benth. and RP-HPLC analysis. BMC Complement Altern Med, 17 (2017), pp. 1-16 
[11] A Pal, RS Pawar. A study on Ajuga bracteosa wall ex. Benth for analgesic activity. Int J Curr Biol Med Sci, 1 (2011), pp. 12-14

[12] ML Mauro, P Costantino, PP Bettini. The never ending story of ro/ genes: a century after. Plant Cell Tiss Org Cult, 131 (2017), pp. 201-212

[13] VP Bulgakov. Functions of ro/genes in plant secondary metabolism. Biotechnol Adv, 26 (2008), pp. 318-324

[14] T Kowalczyk, J Wieczfınska, E Skała, T Śliwiński, P Sitarek. Transgenesis as a tool for the efficient production of selected secondary metabolites from in vitro plant cultures. Plants, 9 (2020), pp. 132

[15] S Rubnawaz, WK Kayani, R Mahmood, B Mirza. Enhanced stress tolerance in transformed Ajuga bracteosa Wall. ex Benth. regenerants by up-regulated gene expression of metabolic pathways. Turk $\mathrm{J}$ Bot, 44 (2020), pp. 410-426

[16] WK Kayani, J Palazòn, RM Cusidò, B Mirza. The effect of rol genes on phytoecdysteroid biosynthesis in Ajuga bracteosa differs between transgenic plants and hairy roots. RSC Advances, 6 (2016), pp. 22700-22708

[17] ZY Hseu. Evaluating heavy metal contents in nine composts using four digestion methods. Bioresour Technol, 95 (2004), pp. 53-59

[18] R Mahmood, F Malik, S Shamas, T Ahmed, M Kausar, S Rubnawaz, et al. Pharmacological evaluation of Rhazya stricta root extract. Bol Latinoam Caribe, 19 (2020), pp. 188-206

[19] X Liu, S Ardo, M Bunning, J Parry, K Zhou, C Stushnoff, et al. Total phenolic content and DPPH radical scavenging activity of lettuce (Lactuca sativa L.) grown in Colorado. LWT-Food Sci Technol, 40 (2007), pp. 552-557

[20] H Ismail, E Dilshad, MT Waheed, M Sajid, WK Kayani, B Mirza. Transformation of Lactuca sativa L. with rol $C$ gene results in increased antioxidant potential and enhanced analgesic, anti-inflammatory and antidepressant activities in vivo. 3 Biotech, 6 (2016), pp. 215

[21] GP Kamatou, AM Viljoen, P Steenkamp. Antioxidant, antiinflammatory activities and HPLC analysis of South African Salvia species. Food Chem, 119 (2010), pp. 684-688

[22] H Ismail, B Mirza. Evaluation of analgesic, anti-inflammatory, anti-depressant, and anti-coagulant properties of Lactuca sativa (CV. Grand Rapids) plant tissues and cell suspension in rats. BMC Complement Aaltern Med, 15 (2015), pp. 199

[23] C Jain, S Khatana, R Vijayvergia. Bioactivity of secondary metabolites of various plants: a review. Int J Pharm Sci Res, 10 (2019), pp. 494-498 
[24] Y Li, D Kong, Y Fu, MR Sussman, $\mathrm{H} \mathrm{Wu}$. The effect of developmental and environmental factors on secondary metabolites in medicinal plants. Plant Physiol Biochem, 148 (2020), pp. 80-89

[25] UV Karpiuk, KM Al Azzam, ZHM Abudayeh, V Kislichenko, A Naddaf, I Cholak, et al. Qualitative and quantitative content determination of macro-minor elements in Bryonia alba L. roots using flame atomic absorption spectroscopy technique. Adv Pharm Bull, 6 (2016), pp. 285

[26] I Zinicovscaia, S Gundorina, K Vergel, D Grozdov, A Ciocarlan, A Aricu, et al. Elemental analysis of Lamiaceae medicinal and aromatic plants growing in the Republic of Moldova using neutron activation analysis. Phytochem Lett, 35 (2020), pp. 119-127

[27] FO Jimoh, AA Adedapo, AJ Afolayan. Comparison of the nutritional value and biological activities of the acetone, methanol and water extracts of the leaves of Solanum nigrum and Leonotis leonorus. Food Chem Toxicol, 48 (2010), pp. 964-971

[28] A Sattar, A Baqi, M Suleman, MT Shah, NK Samiullah. Elemental analysis of medicinal plants and their impacts on human health. Pure Appl Biol, 9 (2020), pp. 249-255

[29] G Mustafa, R Arif, A Atta, S Sharif, A Jamil. Bioactive compounds from medicinal plants and their importance in drug discovery in Pakistan. Matrix Sci Pharma, 1 (2017), pp. 17-26

[30] AK Shakya. Medicinal plants: future source of new drugs. Int J Herb Med, 4 (2016), pp. 59-64

[31] Z Abbas, SM Khan, J Alam, SW Khan, AM Abbasi. Medicinal plants used by inhabitants of the Shigar Valley, Baltistan region of Karakorum range-Pakistan. J Ethnobiol Ethnomed, 13 (2017), pp. 1-15

[32] AG Pereira, M Fraga-Corral, P García-Oliveira, C Jimenez-Lopez, C Lourenço-Lopes, M Carpena, et al. Culinary and nutritional value of edible wild plants from the northern Spain rich in phenolic compounds with potential health benefits. Food Funct, 11 (2020), pp. 8493-8515

[33] S Bibi, M Anwar, HF Hashmi, MR Khan. Evaluation of antioxidant and anti-inflammatory potency of Lepidium pinnatifidum Ledeb. Clin Phytosci 6 (2020), pp. 1-12

[34] E Dilshad, S Zafar, H Ismail, MT Waheed, RM Cusido, J Palazon, B Mirza. Effect of rol genes on polyphenols biosynthesis in Artemisia annua and their effect on antioxidant and cytotoxic potential of the plant. Appl Biochem Biotech, 179 (2016), pp. 1456-1468

[35] BH Kiani, N Ullah, IU Haq, B Mirza. Transgenic Artemisia dubia WALL showed altered phytochemistry and pharmacology. Arab J Chem, 12 (2019), pp. 2644-2654

[36] M Majidinia, A Karimian, F Alemi, B Yousefi, A Safa. Targeting miRNAs by polyphenols: novel therapeutic strategy for aging. Biochem. Pharmacol. 173 (2020), pp. 113688 
[37] R Venkatachalam, K Kalimuthu, V Chinnadurai, M Saravanan, R Radhakrishnan, R Shanmuganathan, et al. Various solvent effects on phytochemical constituent profiles, analysis of antioxidant and antidiabetic activities of Hopea parviflora. Process Biochem, 89 (2020), pp. 227-232

[38] S Zafar, E Dilshad, H Ismail, CB Rizvi, B Mirza. Ro/ genes enhance content of artemisinin and other secondary metabolites in Shennong hybrid of Artemisia annua. Chin Herb Med, 11 (2019), pp. 209-215

[39] H Ismail, E Dilshad, MT Waheed, B Mirza. Transformation of lettuce with rol $A B C$ genes: extracts show enhanced antioxidant, analgesic, anti-inflammatory, antidepressant, and anticoagulant activities in rats. Appl Biochem Biotechnol, 181 (2017), pp. 1179-1198

[40] N Riaz, A Malik, AU Rehman, SA Nawaz, P Muhammad, MI Chaudhary. Cholinesterase-inhibiting withanolides from Ajuga bracteosa. Chem Biodiv, 1 (2004), pp. 1289-1295

[41] R Singh, SM Patil, G Pal, M Ahmad. Evaluation of in vivo and in vitro anti-inflammatory activity of Ajuga bracteosa Wall ex Benth. Asian Pac J Trop Dis, 2 (2012), pp. 404-407.

\section{Tables}

Table 1 Quantity of different elements in aerial parts of Ajuga bracteosa

\begin{tabular}{|c|c|c|c|c|c|c|c|}
\hline & $\lambda_{\max }$ & & Samples & & & & \multirow{12}{*}{$\begin{array}{l}\text { WT = in vitro } \\
\text { grown }\end{array}$} \\
\hline$(\mu \mathrm{g} / \mathrm{mg})$ & $(\mathrm{nm})$ & $(\mathrm{nm})$ & WT & ABRL1 & ABRL2 & ABRL3 & \\
\hline Sodium & 589.0 & 0.5 & $2.86 \pm 0.2$ & $3.54 \pm 0.8$ & $3.07 \pm 1$ & $3.94 \pm 2$ & \\
\hline Potassium & 766.5 & 1.0 & $8.06 \pm 0.3$ & $12.00 \pm 1$ & $12.62 \pm 3$ & $13.09 \pm 2$ & \\
\hline Calcium & 422.7 & 0.5 & $0.50 \pm 0.06$ & $1.69 \pm 0.5$ & $1.32 \pm 0.4$ & $1.95 \pm 0.5$ & \\
\hline Magnesium & 285.2 & 0.5 & $0.91 \pm 0.1$ & $2.15 \pm 0.3$ & $1.12 \pm 0.2$ & $2.12 \pm 0.7$ & \\
\hline Zinc & 213.9 & 1.0 & $0.25 \pm 0.05$ & $0.40 \pm 0.1$ & $0.24 \pm 0.04$ & $0.47 \pm 0.03$ & \\
\hline Iron & 248.3 & 0.2 & $0.25 \pm 0.1$ & $0.33 \pm 0.2$ & $0.46 \pm 0.1$ & $0.44 \pm 0.2$ & \\
\hline Manganese & 279.5 & 0.2 & $0.004 \pm 0.01$ & $0.02 \pm 0.01$ & $0.01 \pm 0.03$ & $0.02 \pm 0.01$ & \\
\hline Nickel & 232.0 & 0.2 & $0.09 \pm 0.02$ & $0.18 \pm 0.1$ & $0.19 \pm 0.1$ & $0.23 \pm 0.2$ & \\
\hline Copper & 324.8 & 0.5 & $0.005 \pm 0.01$ & $0.01 \pm 0.02$ & $0.01 \pm 0.03$ & $0.02 \pm 0.01$ & \\
\hline Chromium & 357.9 & 0.2 & $0.16 \pm 0.03$ & $0.45 \pm 0.1$ & $0.43 \pm 0.2$ & $0.36 \pm 0.1$ & \\
\hline
\end{tabular}

untransformed Ajuga bracteosa plant extract, ABRL1-3=crude extracts of transgenic line 1, 2 and 3 of $A$. bracteosa. Data is represented as mean \pm SD $(n=3)$ 
Table 2 Phytochemical constituents of Ajuga bracteosa

\begin{tabular}{|c|c|c|c|c|c|}
\hline \multirow[t]{2}{*}{ Phytochemicals } & \multicolumn{4}{|c|}{ Samples } & \multirow{2}{*}{$\begin{array}{l}(+) \text { present }(++) \text { moderate concentration } \\
(+++) \text { high concentration }(-) \text { absent. WT= } \\
\text { in vitro arown untransformed Aiuga }\end{array}$} \\
\hline & WT & ABRL1 & ABRL2 & ABRL3 & \\
\hline Alkaloids & ++ & ++ & +++ & +++ & bracteosa plant extract, $A B R L 1-3=$ crude \\
\hline Glycosides & + & +++ & ++ & +++ & extracts of transgenic line 1, 2 and 3 of $A$. \\
\hline Flavonoids & + & ++ & ++ & +++ & $=03 a$ \\
\hline Phenols & ++ & ++ & ++ & ++ & \\
\hline Tannins & + & + & + & + & Table 3 Polyphenolic composition of crude \\
\hline Saponins & + & + & ++ & ++ & extracts of Ajuga bracteosa \\
\hline Terpenoids & - & + & + & + & \\
\hline Coumarins & - & - & - & - & \\
\hline ß-cyanins & - & - & - & - & \\
\hline Anthocyanin & - & - & - & - & \\
\hline Sterols & - & - & - & - & \\
\hline
\end{tabular}




\begin{tabular}{|c|c|c|c|c|c|c|}
\hline \multirow[t]{2}{*}{ Serial no. } & \multirow[t]{2}{*}{ Compound name } & \multirow{2}{*}{$\begin{array}{l}\lambda_{\max } \\
(\mathrm{nm})\end{array}$} & \multicolumn{4}{|c|}{ Extracts ( $\mu \mathrm{g} / \mathrm{mg}$ dry extract) } \\
\hline & & & WT & ABRL1 & ABRL2 & ABRL3 \\
\hline 1 & Vanillic acid & 257 & $8.98 \pm 1$ & $15.87 \pm 3$ & $15.49 \pm 2$ & $16.33 \pm 1$ \\
\hline 2 & Rutin & 257 & $0.63 \pm 0.5$ & $4.49 \pm 1$ & $9.24 \pm 2$ & $14.86 \pm 2$ \\
\hline 3 & Plumbagin & 257 & $\mathrm{Nd}$ & $\mathrm{Nd}$ & $\mathrm{Nd}$ & $\mathrm{Nd}$ \\
\hline 4 & Thymoquinone & 257 & $\mathrm{Nd}$ & $\mathrm{Nd}$ & $\mathrm{Nd}$ & $\mathrm{Nd}$ \\
\hline 5 & Gallic acid & 279 & $4.59 \pm 0.3$ & $14.99 \pm 2$ & $15.01 \pm 3$ & $16.67 \pm 1$ \\
\hline 6 & Catechin & 279 & $\mathrm{Nd}$ & $\mathrm{Nd}$ & $\mathrm{Nd}$ & $\mathrm{Nd}$ \\
\hline 7 & Syringic acid & 279 & $10.79 \pm 0.8$ & $13.93 \pm 2$ & $12.41 \pm 1$ & $17.78 \pm 3$ \\
\hline 8 & Coumaric acid & 279 & $1.92 \pm 0.7$ & $15.39 \pm 3$ & $14.02 \pm 1$ & $23.45 \pm 2$ \\
\hline 9 & Emodin & 279 & $\mathrm{Nd}$ & $\mathrm{Nd}$ & $\mathrm{Nd}$ & $\mathrm{Nd}$ \\
\hline 10 & Gentisic acid & 325 & $\mathrm{Nd}$ & $\mathrm{Nd}$ & $\mathrm{Nd}$ & $\mathrm{Nd}$ \\
\hline 11 & Caffeic acid & 325 & $13.39 \pm 2$ & $25.51 \pm 3$ & $22.01 \pm 2$ & $30.18 \pm 4$ \\
\hline 12 & Ferulic acid & 325 & $75.55 \pm 3$ & $77.17 \pm 4$ & $76.86 \pm 4$ & $78.05 \pm 3$ \\
\hline 13 & Cinnamic acid & 325 & $3.19 \pm 0.7$ & $4.36 \pm 0.5$ & $5.47 \pm 0.2$ & $6.09 \pm 0.3$ \\
\hline 14 & Luteolin & 325 & $\mathrm{Nd}$ & $\mathrm{Nd}$ & $\mathrm{Nd}$ & $\mathrm{Nd}$ \\
\hline 15 & Apigenin & 325 & $8.20 \pm 2$ & $20.84 \pm 5$ & $23.12 \pm 3$ & $32.29 \pm 4$ \\
\hline 16 & Myricetin & 368 & $4.14 \pm 0.7$ & $13.66 \pm 3$ & $11.6 \pm 2$ & $13.37 \pm 4$ \\
\hline 17 & Quercetin & 368 & $4.68 \pm 0.3$ & $6.44 \pm 0.8$ & $7.52 \pm 1$ & $9.19 \pm 0.5$ \\
\hline 18 & Kaempferol & 368 & $17.6 \pm 2$ & $83.9 \pm 4$ & $78.6 \pm 5$ & $101.26 \pm 6$ \\
\hline
\end{tabular}

WT $=$ in vitro grown untransformed Ajuga bracteosa plant extract, ABRL1-3=crude extracts of transgenic line 1,2 and 3 of $A$. bracteosa. Data is represented as mean $\pm S D(n=3)$

\section{Figures}




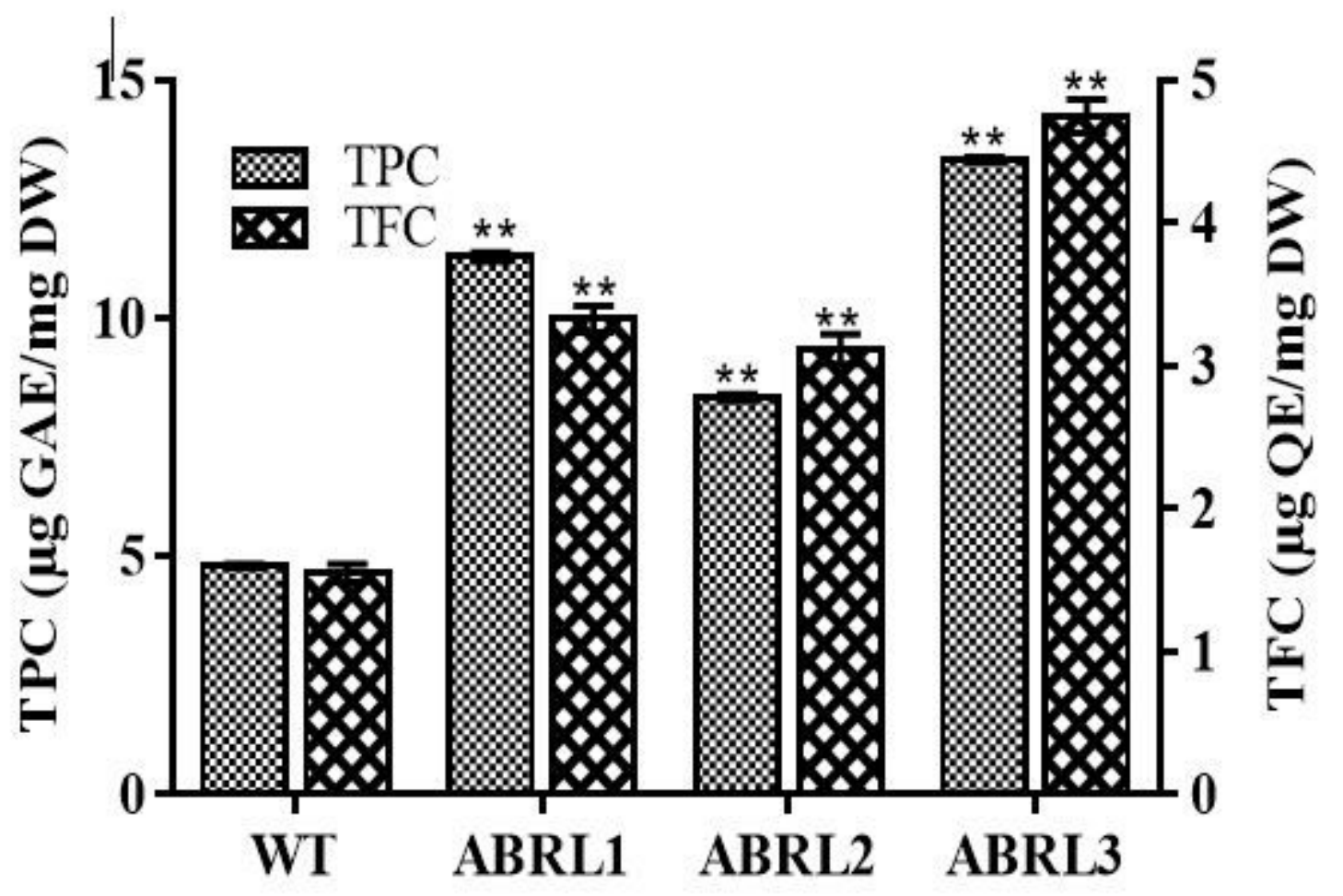

Figure 1

Phytochemical analysis and antioxidant potential of crude extracts of Ajuga bracteosa. (A) Total phenolic and total flavonoids content. WT = wild type untransformed $A$. bracteosa plants, ABRL1-3= Transgenic lines 1-3 of $A$. bracteosa. Each value represents mean $\pm S D(n=3) .{ }^{* \star} p<0.01$ statistical significance 


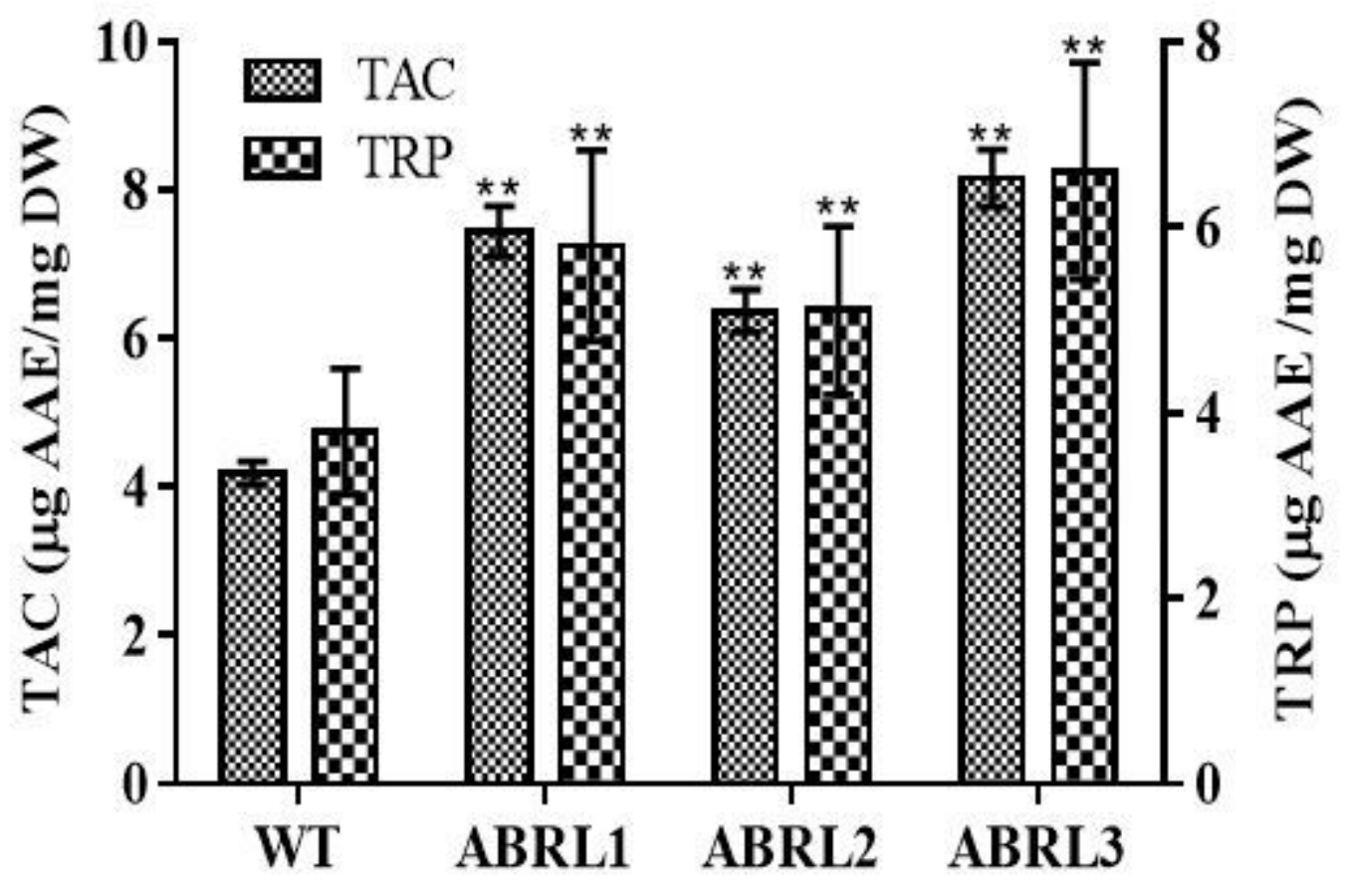

Figure 2

Total antioxidant capacity and total reducing power. WT= wild type untransformed $A$. bracteosa plants, ABRL1-3= Transgenic lines 1-3 of A. bracteosa. Each value represents mean $\pm S D(n=3) .{ }^{*} p<0.01$ statistical significance 
A

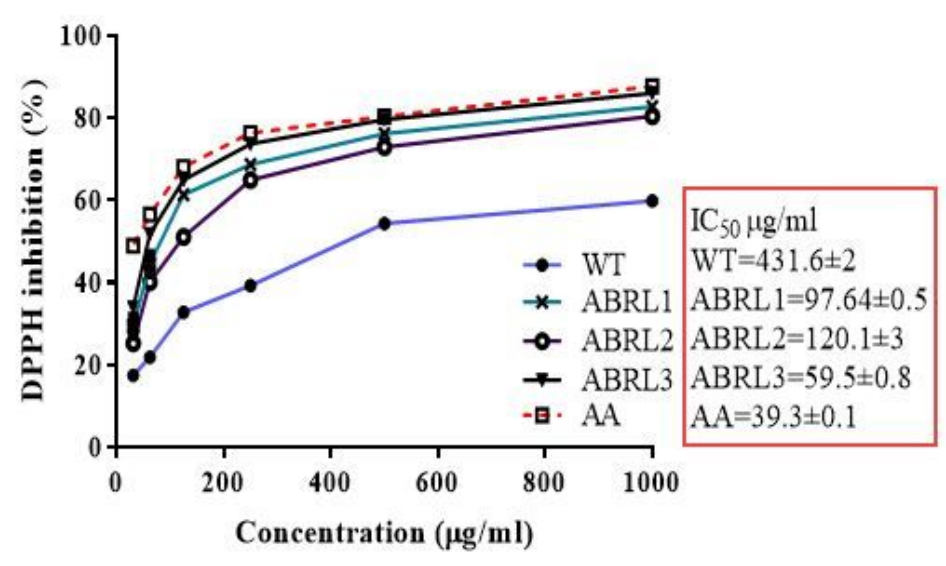

C

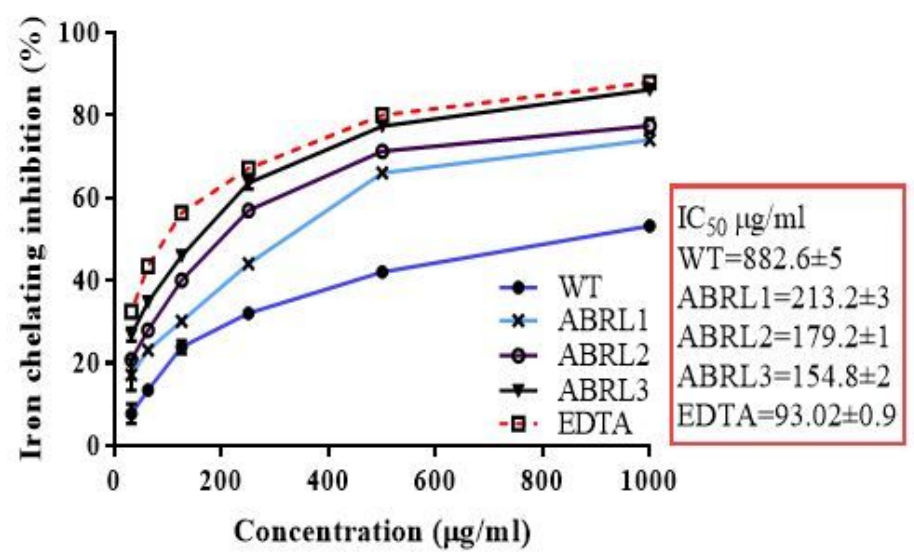

B
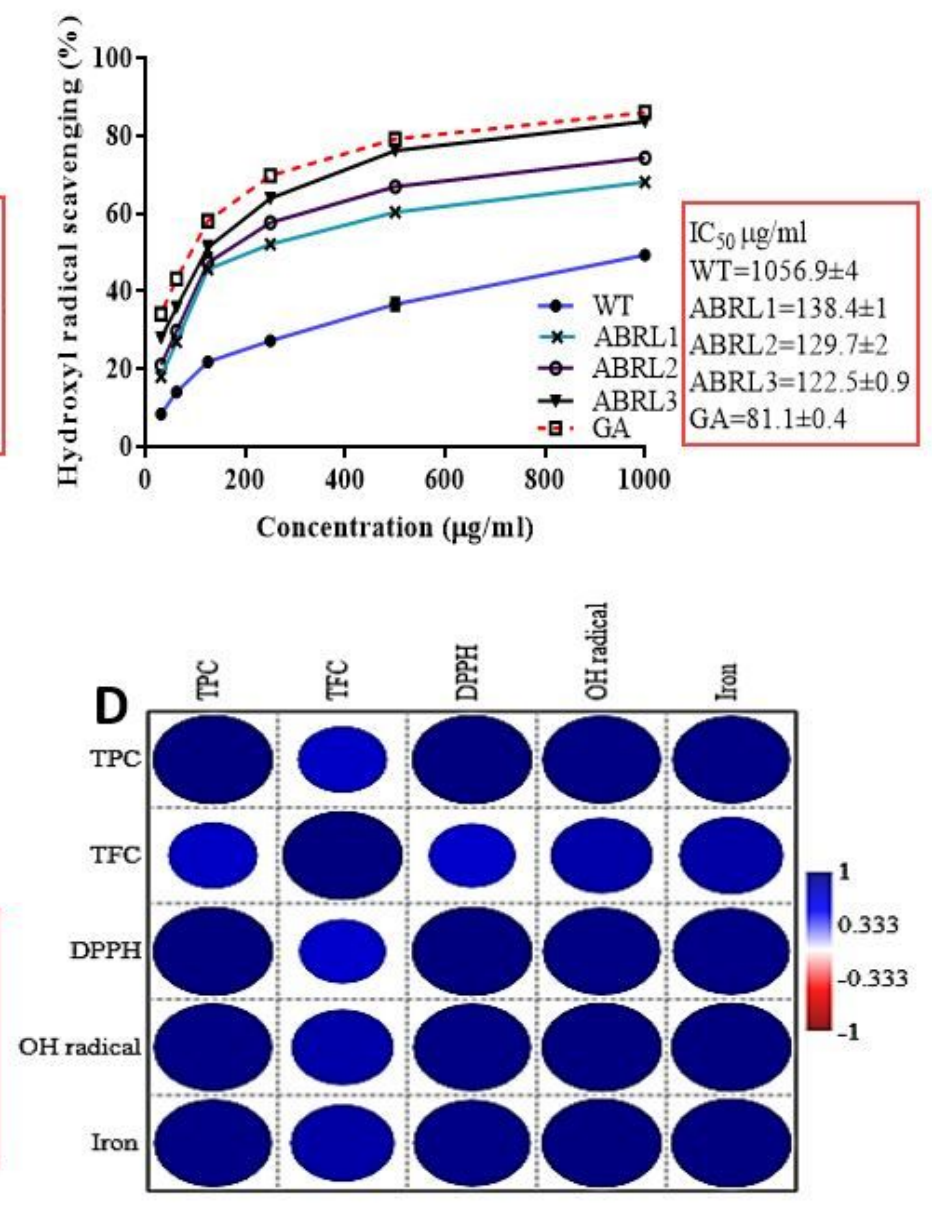

\section{Figure 3}

In vitro Antioxidant activities of crude extracts of Ajuga bracteosa at different concentration. (A) DPPH scavenging activity. (B) Hydroxyl ion scavenging activity. (C) Iron chelating power along with IC50 values. (D) Correlation between TPC, TFC and IC50 values of antioxidant assays. WT= wild type untransformed A. bracteosa plants, ABRL1-3= Transgenic lines 1-3 of A. bracteosa. Each value represents mean \pm SD $(n=3) .{ }^{*} p<0.05,{ }^{* \star} p<0.01$ statistically significant 

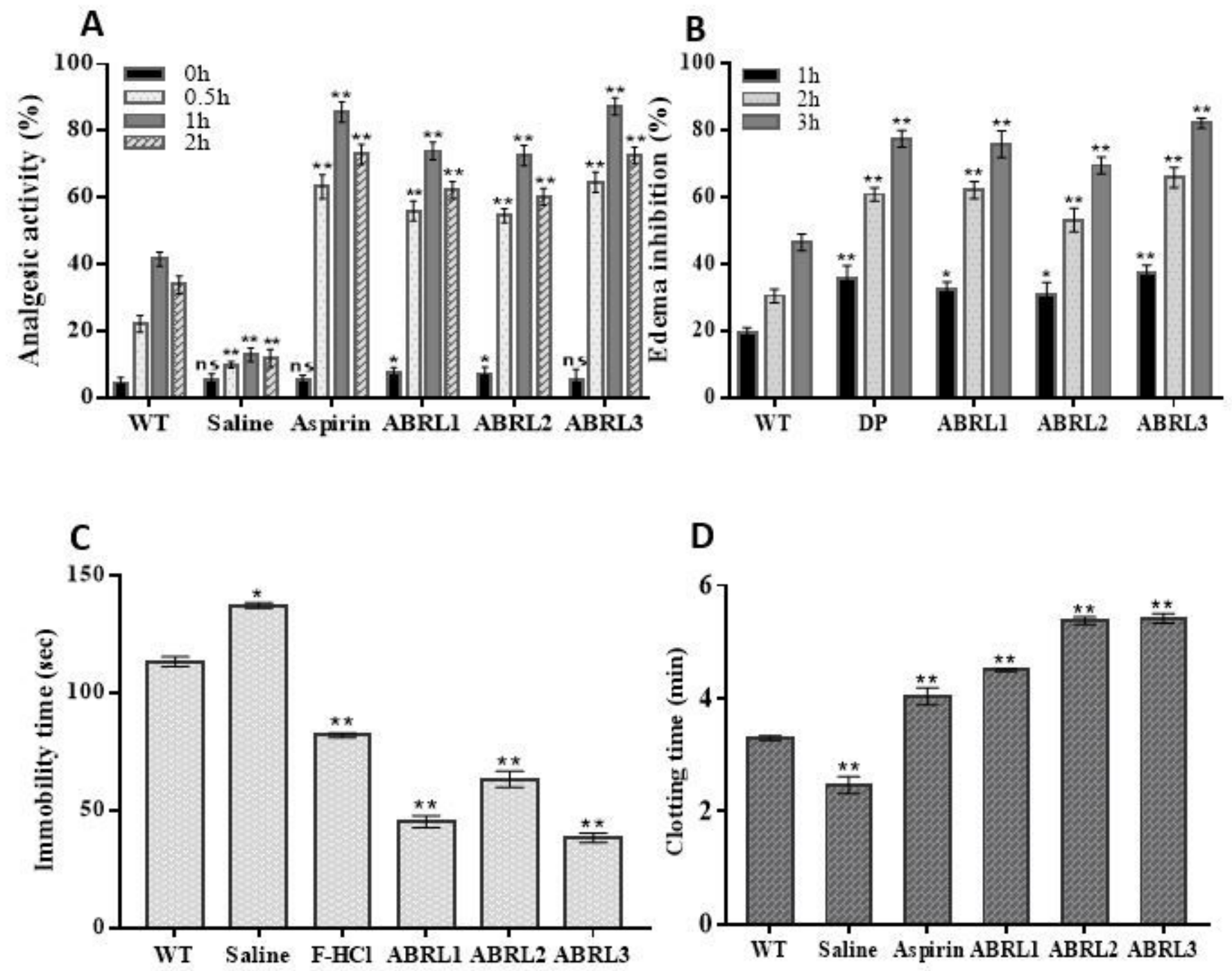

Figure 4

In vivo activities Ajuga bracteosa crude extracts. (A) Analgesic activity. (B) Anti-inflammatory activity. (C) Anti-depressant activity. (D) Anti-coagulant activity. $\mathrm{F}-\mathrm{HCl}=$ Fluoxetine $\mathrm{HCl}, \mathrm{DP}=$ Diclofenac Potassium WT = wild type untransformed A. bracteosa plants, ABRL1-3= Transgenic lines 1-3 of A. bracteosa. Each value represents mean $\pm S D(n=5)$. ns shows non-significant, ${ }^{*} p<0.05,{ }^{\star \star} p<0.01$ statistically significant data

\section{Supplementary Files}

This is a list of supplementary files associated with this preprint. Click to download.

- Supplementaryfile.docx 